\title{
Typha latifolia L. (Typhaceae), nuevo registro para la flora de Chile
}

\section{Typha latifolia L. (Typhaceae), new record for the Chilean flora}

\author{
Jonathan Urrutia ${ }^{1,2 *}$, Alicia Marticorena ${ }^{3}$ \& Paulina Sánchez ${ }^{1,2}$ \\ ${ }^{1}$ Facultad de Ciencias Forestales, Universidad de Concepción, Laboratorio de Invasiones Biológicas (LIB), Casilla 160-C, \\ Concepción, Chile. \\ ${ }^{2}$ Instituto de Ecología y Biodiversidad (IEB), Casilla 653, Las Palmeras 3425, Ñuñoa, Santiago, Chile. \\ ${ }^{3}$ Departamento de Botánica, Facultad de Ciencias Naturales y Oceanográficas, Universidad de Concepción, Casilla 160-C, \\ Concepción, Chile. \\ *jurrutiaestrada@gmail.com
}

\begin{abstract}
For first time in Chile, is documented the presence of Typha latifolia L., a species that occurs mainly in wetlands, and up to date it was only registered in neighboring countries. This new species record was found in the Talcahuano area, Biobío Region. A morphological description of the plant is provided and also an identification key for the species of the Typha genus growing in Chile.
\end{abstract}

Typha L. (Typhaceae) es un género compuesto aproximadamente por 15 especies de distribución casi cosmopolita. Se encuentra en una amplia variedad de ambientes acuáticos y palustres alrededor del mundo, adoptando un hábito emergente (Cook 1990). Hasta la fecha en Chile se conocían dos especies, T. angustifolia L. y $T$. domingensis Pers. (Gunckel 1959, Marticorena \& Quezada 1985, Zuloaga et al. 2008). Typha latifolia L., aunque se trata de una especie de amplia distribución mundial (Canadá, Estados Unidos, México, Guatemala, Gabón, China), no había sido registrada para Chile, sin embargo se encuentra presente en los tres países que limitan con el territorio nacional, Bolivia (Jørgensen et al. 2014), Perú (Brako \& Zarucchi 1993) y Argentina (Crespo \& Perez-Moreau 1967, Zuloaga et al. 2008).

Durante prospecciones florísticas realizadas el 2013 en la Región del Biobío, se registró la presencia de una especie del género Typha desconocida hasta el momento. Dicho taxa fue recolectado por Urrutia en la comuna de Talcahuano $\left(36^{\circ} 45^{\prime} 41,59^{\prime \prime} \mathrm{S}-73^{\circ} 07^{\prime} 11,72^{\prime \prime} \mathrm{O}\right)$ a $16 \mathrm{msnm}$. Estudios posteriores realizados a los especímenes recolectados revelaron que la identidad de dicha planta correspondía a Typha latifolia (Fig. 1).

\section{DESCRIPCIÓN}

Typha latifolia L., Sp. Pl. 2: 971. 1753 “Habitat in paludibus Europae".

Plantas de 1-3 m de altura. Hojas que sobrepasan, igualan o no alcanzan la inflorescencia; vainas paulatinamente continuadas en las láminas hasta auriculadas; aurículas simétricas o asimétricas, notoriamente marcadas en las hojas superiores; lámina de $45-120 \mathrm{~cm}$ de largo por 0,6$2 \mathrm{~cm}$ de ancho, haz plano, envés levemente convexo casi plano. Inflorescencias con una o más brácteas foliáceas caducas (Fig. 1A). Espigas masculinas de 10-28 cm de largo por $0,7-1,5 \mathrm{~cm}$ de ancho, suavemente cónicas y en general unidas a las femeninas, a veces separadas por una pequeña porción de raquis. Flores masculinas con 1-5 estambres, predominando 2, por excepción hasta 7; filamentos de 1-6 mm de largo; anteras de 1,2-3 mm de largo total con el ápice del conectivo generalmente obtuso. Polen en tétradas. Bractéolas filiformes de 3-6 mm de largo. Espigas femeninas color castaño-oscuro, de $12-43 \mathrm{~cm}$ de largo por 1,5-3 cm de ancho, frecuentemente un poco más anchas en la parte superior. Raquis secundarios 20-30 por $\mathrm{mm}^{2}$, filiformes (Fig. 1B), de 1,5-3,5 mm de altura, de base ensanchada y con escalones que se hacen muy espaciados hacia la parte superior. Flores femeninas fértiles, de 7-10,5 $\mathrm{mm}$ de largo, ovario fusiforme, estigma lanceolado. Flores femeninas estériles de 4,5-8 cm de largo, ovario obovoide. Fruto fusiforme de 1-1,5 cm de largo.

Esta especie habita en pantanos, estanques, márgenes de lagos, estuarios, praderas húmedas, canales de irrigación, y campos de cultivo de arroz (Fig 1C). Tolera sustratos ácidos, alcalinos y condiciones ligeramente salinas (DiTomaso \& Healy 2003). 
MATERial ESTUdiado

CHILE: Región del Biobío, Provincia de Concepción, a 5 $\mathrm{km}$ de la ciudad de Talcahuano. $16 \mathrm{msnm}$. $36^{\circ} 45^{\prime} 41.59^{\prime \prime} \mathrm{S}$ -7307'11.72”O. 10-XII-2013, J. Urrutia Estrada (CONC 182462).
Es probable que esta especie se encuentre presente desde hace tiempo en el país, pero debido a que los caracteres que la diferencian de sus congéneres son poco evidentes, ha pasado inadvertida. A continuación se presenta una clave para identificar a las especies del género Typha que crecen en Chile.

1. Inflorescencia con raquis secundarios filiformes. Polen en tétradas. Espigas masculinas en general unidas a las femeninas. Hojas de 0,6 a $2 \mathrm{~cm}$ de ancho. T. latifolia 1'. Inflorescencia con raquis secundarios nunca filiformes. Polen simple. Espigas masculinas en general separadas de las femeninas por una porción de raquis.

2. Raquis secundarios siempre subpiramidales, escalariformes, a veces truncados. Anteras de 1,8-3 mm de largo total; apéndice del conectivo variable, obtuso hasta apiculado. Hojas de 0,5 a 1,6 cm de ancho. T. domingensis

2'. Raquis secundarios de base algo escalariforme pero subcilíndricos en la mitad superior. Anteras de 1,5-2,5 mm de largo total; apéndice del conectivo en general obtuso. Hojas de 0,3 a $0,7 \mathrm{~cm}$ de ancho. ..T. angustifolia
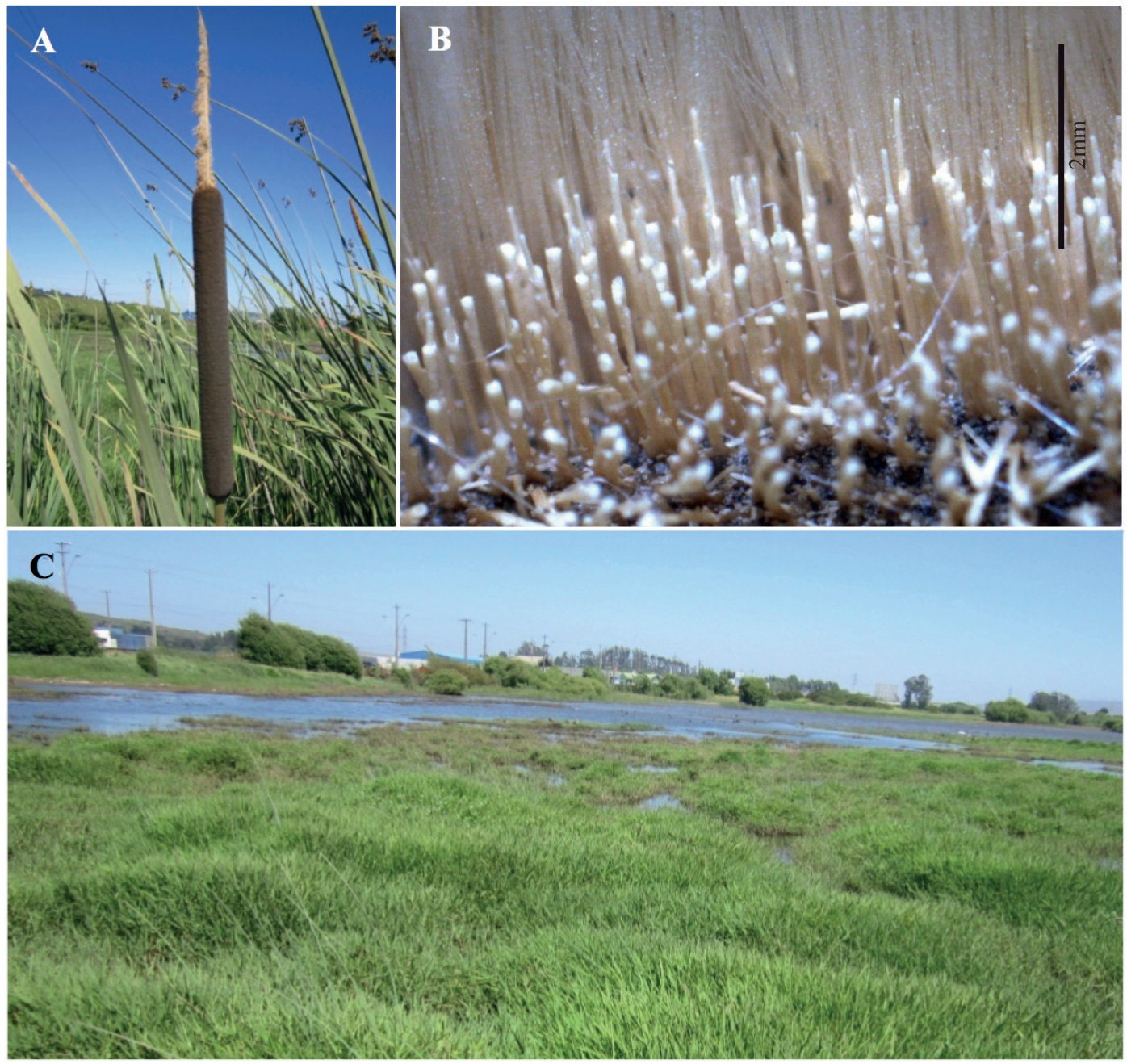

Figura 1. Typha latifolia. A: inflorescencias, B: raquis secundarios, C: hábitat (humedal en Talcahuano). / Typha latifolia. A: inflorescences, B: secondary rachis, C: habitat (wetland in Talcahuano). 


\section{AGRADECIMIENTOS}

A los proyectos ICM P05-002 y PFB-23.

\section{LITERATURA CITADA}

Brako, L., Zarucchi, J. 1993. Catalogue of the flowering plants and gymnosperms of Perú. Monographs in Systematic Botany from the Missouri Botanical Garden Press, Saint Louis, USA. 1286 pp.

Cook, C. 1990. Aquatic plant book. SPB Academic Publishing, The Hague, Netherlands. 228 pp.

Crespo, S., Pérez-Moreau, R. 1967. Revisión del género Typha en la Argentina. Darwiniana 14: 413-429.
DiTomaso, J., Healy, E. 2003. Aquatic and riparian weeds of the west. University of California, California. $442 \mathrm{pp}$.

Gunckel, H. 1959. Flora vascular de Chile. Tifáceas. Instituto de Botánica, Universidad de Chile 1: 1-6.

Jørgensen, P., Nee, M., Beck, S. 2014. Catálogo de las plantas vasculares de Bolivia, Monographs in Systematic Botany from the Missouri Botanical Garden. 1744 pp.

Marticorena, C., Quezada, M. 1985. Catálogo de la flora vascular de Chile. Gayana Botánica 42: 5-157.

Zuloaga, F., Morrone, O., Belgrano, M. (eds.). 2008. Catálogo de las Plantas Vasculares del Cono Sur (Argentina, sur de Brasil, Chile, Paraguay y Uruguay). Monographs in Systematic Botany from the Missouri Botanical Garden. Missouri Botanical Garden Press, Saint Louis, USA. $3884 \mathrm{pp}$.

Recibido: 16.12 .2015

Aceptado: 31.05.2017 